\title{
Ameliorating Effect of Green Tea Aqueous Extract against Histo pathophysiological Changes Induced by Ciprofibrate in the liver of Male Albino Rats
}

\author{
Fikry Ali Abushofa ${ }^{1}$, Azab Elsayed Azab ${ }^{2 *}$, Tahani S. AL-Jelany Sakah ${ }^{3}$, and Nadia M. Kermani ${ }^{4}$ \\ ${ }^{1,4}$ Department of Zoology, Faculty of Science, Zawia University, Libya \\ ${ }^{2}$ Department of Physiology, Faculty of Medicine, Sabratha University, Libya \\ ${ }_{3}^{3}$ Department of Biological Sciences, School of Basic Sciences, Libyan Academy of Graduate Studies, Tripoli, Libya. \\ Corresponding Author: Azab Elsayed Azab, Department of Physiology, Faculty of Medicine, Sabratha University, Libya. \\ Received date: November 26, 2020; Accepted date: November 30, 2020; Published date: December 12,2020 \\ Citation: Fikry A. Abushofa, Azab E. Azab, Tahani S. AL-Jelany Sakah and Nadia M. Kermani (2020) Ameliorating Effect of Green Tea Aqueous \\ Extract against Histopathophysiological Changes Induced by Ciprofibrate in the liver of Male Albino Rats J, Biotech. and Bioprocessing 1(3); DOI: \\ 10.31579/2766-2314/013
}

Copyright: (C) 2020, Azab Elsayed Azab, This is an open access article distributed under the Creative Commons Attribution License, which permits unrestricted use, distribution, and reproduction in any medium, provided the original work is properly cited.

\section{Abstract}

Background: The liver is a specific target for drug toxicity because of its role in removal and metabolism of chemicals by converting drugs into another forms that can be readily removed from the body. It is known that the main function of the liver is the elimination of toxins that may enter the body, thus becoming vulnerable damaged during this mechanism, which can be revealed as bleeding, congestion, necrosis or other conditions of liver injury. Ciprofibrate belongs to widely used class of lipid-regulating agents, which stimulate hepatic cells and the hepatic cell becomes uncontrollably divided, causing liver growth. It causes liver cell proliferation in addition to other pleiotropic effects such as peroxisome proliferation and induction of certain peroxisomal and cytosolic enzymes in liver.

Objective: The present study aimed to evaluate the potential beneficial effects of green tea aqueous extract administration against the biochemical and histological alterations induced in the liver by ciprofibrate in male rats. Materials and Methods: In the current study 3 groups of 6 male rats were used (Control group, $100 \mathrm{mg} \backslash \mathrm{Kg}$ body weight, and Cipro $100 \mathrm{mg} \backslash \mathrm{Kg}$ body weight with green tea). The rats have been treated daily orally by gavages for 21 days. On the last day of the experiment the animals were killed then blood samples and parts from the liver were collected. Liver function was examined for the serum Alanine Aminotransferase (ALT), Aspartate Aminotransferase (AST), alkaline phosphates (ALP), enzyme activities, and serum total \& direct bilirubin concentrations. The histopathological investigation was conducted for the liver tissues of all groups.

Results: Treatment of male rats with $100 \mathrm{mg} \backslash \mathrm{Kg}$ body weight of ciprofibrate caused a significant increase in serum ALT, AST, and ALP activities, total, and direct bilirubin concentration. Histologically, there were histological changes in central vein area and portal zones, revealed congestion in blood sinusoids, necrosis in hepatic cells, and damage in central vein lining epithelium. Co-administration of green tea aqueous extract with Ciprofibrate significantly improved the structural changes in the liver and the serum ALT, AST, and ALP activities, total, and direct bilirubin concentrations were significantly declined.

Conclusion: It can be concluded that Ciprofibrate treatment induced elevation in liver function tests and severe histopathological changes and green tea aqueous extract was able to protect the liver against these effects in male rats. So, the patients should be advised to take green tea aqueous extract while they are treated by ciprofibrate.

Key words: hypolipidemic agent; ciprofibrate; green tea aqueous extract; hepatotoxicity; hepatophysiological change

\section{Introduction}

The liver is responsible for the metabolism of xenobiotics and endogenous hormones, and the detoxification of exogenous compounds [1]. It is known that the main function of the liver is the elimination of toxins that may enter the body, thus becoming vulnerable damaged during this mechanism, which can be revealed as bleeding, congestion, necrosis or other conditions of liver injury [2].
The liver plays an essential role in transforming and clearing chemicals and is susceptible to the toxicity from these agents. The drugs can be administered to the body by many ways, including orally, intramuscular injection, intravenous, dermal absorption, and nasally [3]. Some medicinal agents, when taken in overdoses and sometimes even when introduced within therapeutic ranges, may lead to serious adverse effects. The liver is a specific target for drug toxicity because of its role in removal 
and metabolism of chemicals by converting drugs into another forms that can be readily removed from the body.

Peroxisome proliferators are a diverse group of chemicals which differs slightly in structure but all induce characteristic effects in the liver of treated rats and mice [4]. Peroxisome proliferators include many chemicals which are unrelated structurally such as hypolipidemic drugs plasticizers and organic solvents, all of which cause liver carcinogenesis in laboratory rodents by a non-genotoxic mechanism. Ciprofibrate belongs to widely used class of lipid-regulating agents, which associated with a variety of effects on lipid and lipoprotein metabolism [5]. These effects reduce the risk of developing sclerosis arterial heart disease and stroke. Although it has been clinically used since 1930, the mechanism of action of ciprofibrate is not entirely clear in 1990. Peroxisome proliferation is accompanied by replicative DNA synthesis and liver growth. Many of these peroxisome proliferators contain acid functions that can modulate fatty acid metabolism [6]. Liver enlargement induced by peroxisome proliferators is due to both hepatocyte hyperplasia (increased replicative DNA synthesis and cell division) and hypertrophy [7]. Peroxisome proliferators cause liver cell proliferation in addition to other pleiotropic effects such as peroxisome proliferation and induction of certain peroxisomal and cytosolic enzymes in liver [8]. Liver damage is indicated by an increase in liver enzymes such as alanine aminotransferase (ALT) in the serum [9].

Long term administration of peroxisome proliferators produces sustained oxidative stress in rodent hepatocytes due to an imbalance in the production and degradation of hydrogen peroxide [10]. The increased intracellular levels of hydrogen peroxide can attack membranes and DNA either directly or through other reactive oxygen species (ROS). These radicals interact with cell components and change their structure and function which in turn lead to various metabolic changes and biological functions disorders including cancer [11].

Recently, the trend increased towards herbal medicine which have antioxidant activities that can slow or stop oxidation reactions and have shown positive effects against some diseases. Green tea (Camellia sinensis L.) is a popular drink consumed daily by millions of people worldwide [12]. It has been reported that drinking green tea has a beneficial effect, by reducing the development or the enhancement of oxidative stress and, therefore, protecting the individual for oxidative stress diseases [13]. Previous studies reported many beneficial effects of green tea such as anti-inflammatory [14], antimutagenic, anticarcinogenic [15], hypochlosterolemic [16], anti-neurodegenerative [17], and antioxidative [18] properties. The health benefits attributed to the consumption of green tea are thought to be linked with its high content of bioactive components such as polyphenols and flavonoids [19]. These bioactive phytochemicals of green tea (GT) shown to be responsible for its antioxidant activity [20]. Catechins: epicatechin (EC), epigallocatechin (EGC), epicatechin-3-gallate (ECG) and epigallocatechin-3-gallate (EGCG) are the main polyphenols in GT [21]. In addition, GT also contains tannins and alkaloids, such as tristetraprolin, caffeine, theobromine and theophylline [22].

Besides its antioxidant activity, GT components could also possess other Pharmacological activities, such as the ability to reduce the risk of type 2 diabetes and lower glucose [23], lipid profile, plasma oxidized LDL [24], and uric acid [25] concentrations. The consumption of green tea was found to decrease the nicotine-induced toxicity by regulating the antioxidant- and inflammation-related genes [24]. Oral green tea aqueous extract reduced the negative effects of $\mathrm{CCl} 4$ and corrected all examined biomarkers toward the control values. The protective effects of green tea aqueous extract were in the form of improving of serum transaminases, decreasing of hepatic lipid peroxidation and activation of hepatic antioxidant enzymes. Also, green tea corrected the values of glucose and total protein towards the control group values in $\mathrm{CCl} 4$ intoxicated rats
[26]. Recent studies have shown that epigallocatechin-3-gallate (EGCG) may be a promising therapeutic or protective agent against hypertension and various kidney diseases [27, 28].

\section{Objectives}

This study was undertaken to investigate the possible hepatoprotective effect of green tea aqueous extract against ciprofibrate induced liver injury in adult male rats.

\section{Material and methods}

\subsection{Animals}

Male rats (14-15 weeks, $200 \pm 25 \mathrm{gm}$ ) were purchase from were purchased from Animal Welfare House of Libyan National Medical Research Centre, Zawia, Libya. They were housed in plastic cages, 6 rats per cage and left one week of acclimation before starting the experiment. The rats were kept in a room at $22 \pm 2{ }^{\circ} \mathrm{C}$, under controlled environmental conditions with humidity $(65+5 \%)$ and $12 \mathrm{~h}$ day: $12 \mathrm{~h}$ night cycle. Rats had free access to standard food and water ad libitum.

\subsection{Chemicals}

Ciprofibrate was purchased from Sigma-Aldrich (St. Louis, MO, USA). Ciprofibrate powder was dissolved in $20 \mathrm{ml}$ of corn oil. Rats received either 50 and $100 \mathrm{mg} \backslash \mathrm{Kg}$ b.wt. dose by oral gavage as described previously [29].

\subsection{Preparation of green tea aqueous extract}

Green tea was purchased from the local market. Aqueous extract was prepared according to Khan et al. [30] by soaking 30 grams of green tea leaves in 1 litter of boiling distilled water for 5 minutes and filtered the solution to make a $3 \%$ of green tea extract. This extract poured into the animals feeding bottles and provided to all rats as their sole source of drinking water.

\subsection{Methods}

\subsubsection{Experimental study design}

The animals were left for a week for the purpose of acclimation before starting the experiment. The animals were divided randomly into 3 groups after weighting, each group consists of 6 rats as shown below. The experiment continued 21 days and at the end of three weeks treatment, animals were weighted and sacrificed.

G1: Control group; It was given corn oil at the same time as other treated group and feed normal diet and tap water.

G4: Ciprofibrate group: Ciprofibrate $100 \mathrm{mg} \backslash \mathrm{Kg}$ b.wt.

G5: Treated group: Ciprofibrate $100 \mathrm{mg} \backslash \mathrm{Kg}$ b.wt. + Green tea.

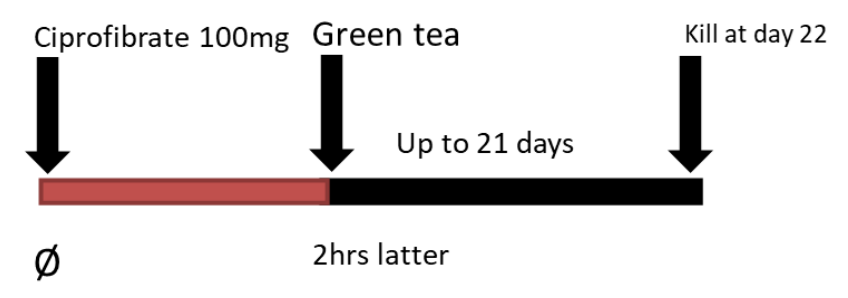

Figure A. Schematic representation of two dose protocol. The schematic diagram describes the two doses protocol of hepatic induction by peroxisome proliferator (ciprofibrate $100 \mathrm{mg}$ ) after administration with $3 \%$ green tea at time $\varnothing$. The red bar shows the period where the animals were gavaged with $100 \mathrm{mg}$ ciprofibrate. The black shows the period where the animals were gavage with green tea. 


\subsubsection{Biochemical studies}

After the animals were anesthetized with ether, the blood samples were collected through cardiac puncture into centrifuge tubes. Blood samples were centrifuged at $3000 \mathrm{rpm}$ for 20 minutes and serum was separated and analyzed for the assessment of liver enzymes; alanine amino transferase (ALT), alkaline phosphatase (ALP) and aspartate amino transferase (AST). Serum total and direct bilirubin levels were also determined.

\subsubsection{Tissue processing}

Liver tissue was freshly collected from the animals and fixed in $10 \%$ formalin saline. After the fixing, the tissues were processed for Hematoxylin and Eosin staining techniques. Tissues then dehydrated and infiltrated with paraffin wax by processing in Thermo Scientific Shandon Citadel-Automated Tissue processor. Tissues were removed and embedded in paraffin and kept overnight at room temperature. The paraffin blocks were kept until sectioning. Paraffin sections were prepared $(4.5 \mu \mathrm{m}$ thick), stained with $\mathrm{H} \& \mathrm{E}$, examined with a light microscope and photographed.

\subsection{Statistical analysis}

Graph Pad Prism 7.0 (Graph Pad Software Inc., La Jolla, CA, USA) was used for all data analysis. The results are expressed as mean \pm standard deviation. Statistical significance was tested by Dunnett's Multiple Comparison Test with one ways analysis of variance (ANOVA). A value of $p<0.05$ was considered to indicate a significant difference between groups.

\section{Results}

\subsection{Biochemical parameters of the liver}

Three aspects have been used which are; Biochemical analysis, histopathological study and verify to cell proliferation. The animals were induced with ciprofibrate $100 \mathrm{mg} \backslash \mathrm{Kg}$ b.wt.

\subsubsection{Effect of ciprofibrate and \or ciprofibrate with green tea on serum liver function:}

\section{1.1.1. Serum liver enzymes activities:}

Generally, ciprofibrate has elevated the liver enzymes strongly such as ALT, AST and ALP. The result of give rats $100 \mathrm{mg} \backslash \mathrm{Kg}$ b.wt. Ciprofibrate (gavages) once a day for 21 days, caused a significant $(\mathrm{P}<0.01)$ increase in serum Alanine Aminotransferase (ALT), Aspartate Amino transferase (AST), and alkaline phosphates (ALP) compared with the control group. But, treatment of rats with ciprofibrate $100 \mathrm{mg} \backslash \mathrm{Kg}$ b.wt with green tea caused a significant decrease in serum ALT, AST and ALP compared with the treated group with ciprofibrate only (Table. $1 \&$ Figure. 1).

\begin{tabular}{|c|c|c|c|}
\hline \multirow{2}{*}{ Parameters(ULL) } & \multicolumn{3}{|c|}{ Groups } \\
\cline { 2 - 4 } & Control & Cipro 100mg & Cipro100mg $\backslash$ Kg with green tea \\
\cline { 2 - 4 } & Mean \pm SD & Mean \pm SD & Mean \pm SD \\
\hline Alanine aminotransferase(ALT) & $64.3 \pm 0.9$ & $174 \pm 1.9^{* *}$ & $105.2 \pm 0.8^{* * \# \#}$ \\
\hline Aspartate aminotransferase(AST) & $86 \pm 0.8$ & $181.2 \pm 1.4^{* *}$ & $136 \pm 1.1^{* * \# \#}$ \\
\hline Alkaline phosphatise (ALP) & $141.3 \pm 0.6$ & $263 \pm 2.3^{* *}$ & $220 \pm 1.3^{* * \# \#}$ \\
\hline
\end{tabular}

**: $\mathrm{P}<0.01$ statistically high significant difference between control and treated.

\#\#: $\mathrm{P}<0.01$ statistically high significant difference between Ciprofibrate and Ciprofibrate100mg+ green tea.

Table 1. Effects of treatment with ciprofibrate and $\backslash$ or ciprofibrate with green tea on the serum activities of ALT, AST, and ALP in male albino rats.

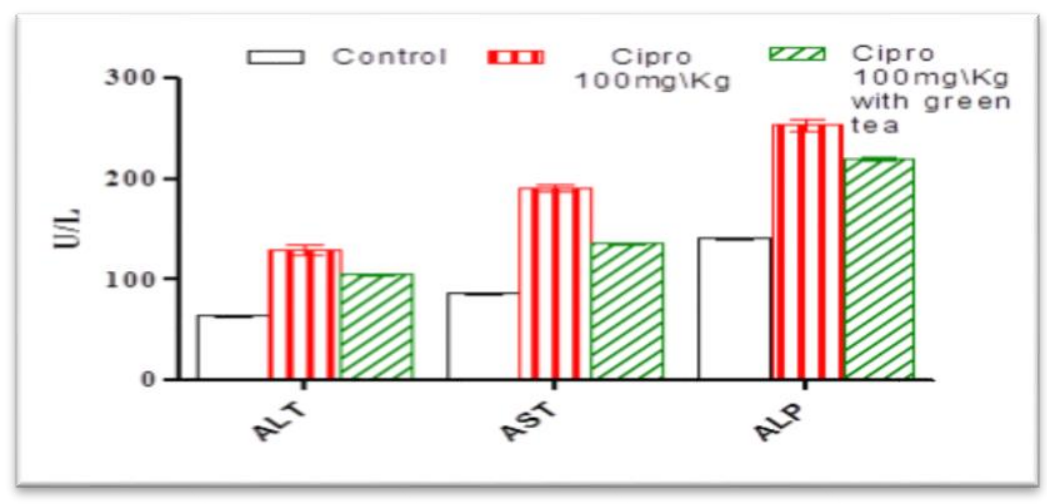

Figure 1. Effects of treatment with ciprofibrate andlor ciprofibrate with green tea on the serum activities of ALT, AST, and ALP in male albino rats.

\section{1.1.2. Serum total bilirubin and bilirubin direct levels}

Treatment of rats with $100 \mathrm{mg} \backslash \mathrm{Kg}$ b.wt. Ciprofibrate (gavages) once a day for 21 days, caused a significant $(\mathrm{P}<0.01)$ increase in the levels of serum total bilirubin and direct bilirubin compared with the control group. But, treatment of rats with ciprofibrate $100 \mathrm{mg} \backslash \mathrm{Kg}$ b.wt with green tea caused a significant decrease in the levels of serum total bilirubin and direct bilirubin compared with the treated group with ciprofibrate only (Table. 2 \& Figure. 2)

\begin{tabular}{|c|c|c|c|}
\hline \multirow{2}{*}{ Parameters(g\dI) } & \multicolumn{3}{|c|}{ GROUPS } \\
\cline { 2 - 4 } & Control & Cipro 100mg\Kg & Cipro100mg\Kg with green tea \\
\cline { 2 - 4 } & Mean \pm SD & Mean \pm SD & Mean \pm SD \\
\hline Total bilirubin & $2.9 \pm 0.02$ & $4.6 \pm 0.06^{* *}$ & $4.3 \pm 0.003^{* * \#}$ \\
\hline Direct bilirubin & $1.1 \pm 0.01$ & $2.9 \pm 0.002^{* *}$ & $2.0 \pm 0.08^{* * \# \#}$ \\
\hline
\end{tabular}


**: $P<0.01$ statistically high significant difference between control and treated.

\#\#: $P<0.01$ statistically high significant difference between Ciprofibrate and Ciprofibrate100mg+ green tea

Table 2. Effects of treatment with ciprofibrate andlor ciprofibrate with green tea on the serum levels of total Bilirubin and direct bilirubin in male albino rats.

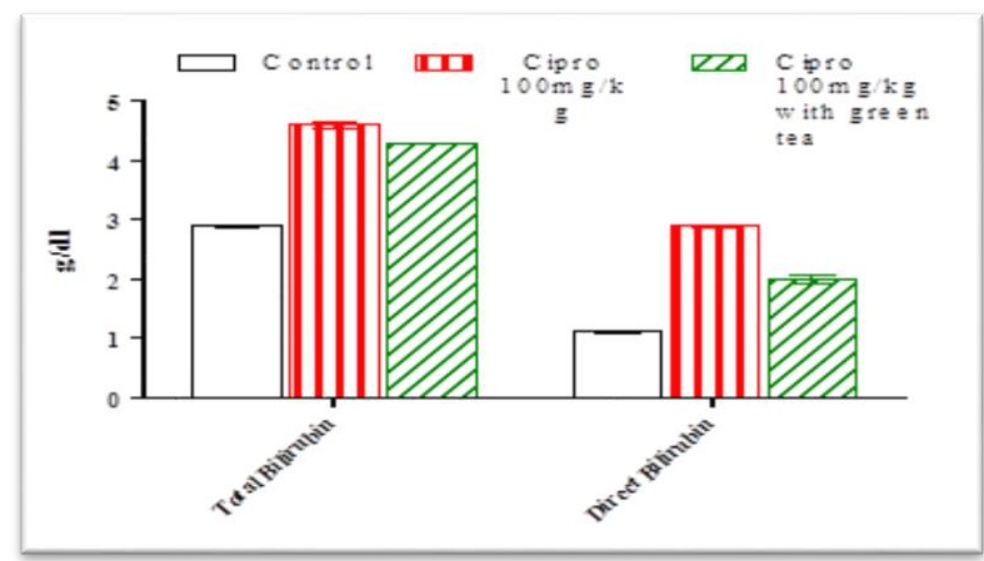

Figure 2. Effects of treatment with ciprofibrate and $\backslash$ or ciprofibrate with green tea on the serum levels of total Bilirubin and direct bilirubin in male albino rats.

\subsection{Histopathological changes of liver}

\subsubsection{The central vein alteration:}

In order to verify the accuracy of the results obtained from the biochemical analysis of liver serum enzymes of all night groups. The liver tissue sections were divided into two mains structural units which are:
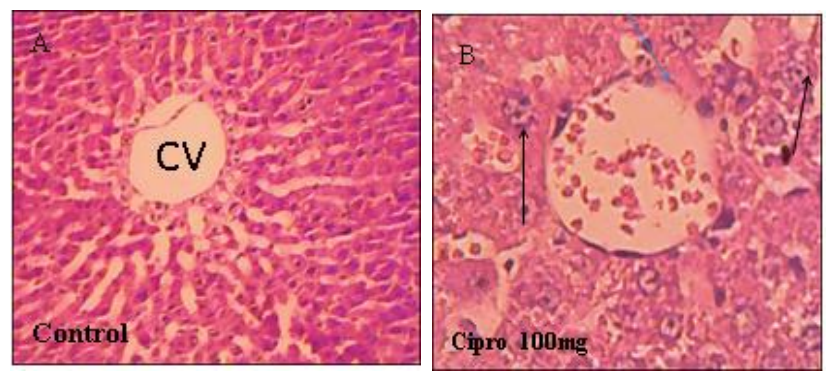

central vein and portal area which were deeply looked. As a result of ciprofibrate induction with $50 \mathrm{mg}$ and $100 \mathrm{mg}$ showed massive cell division. Figure (3) for central vein (CV) which reveals normal lining endothelial, normal hepatocytes radiating arrangement from central vein and blood sinusoids appear between the hepatocytes. The Variation in the central vein $(\mathrm{CV})$ is shown in (3) micrographs.
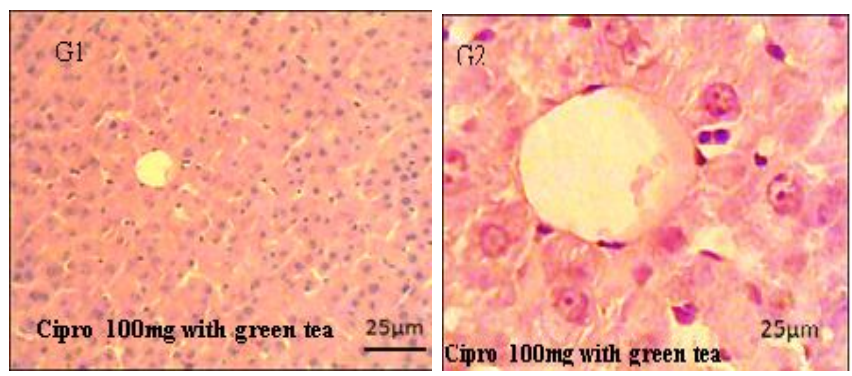

Figure 3. Liver rat sections were gavaged either 50 or $100 \mathrm{mg} \backslash \mathrm{Kg}$ b. wt. of ciprofibrate with or without green tea. (A) Liver section from control groups shows normal histology structure of center vein (C.V). (B) Section from induced group with $100 \mathrm{mg} \backslash \mathrm{Kg}$ b. wt. of ciprofibrate; shows congestion in sinusoids and damage in lining endothelium blue arrow, also destruction in hepatocytes, and necrosis black arrow. (G) Section of the liver rat from ciprofibrate $100 \mathrm{mg} \backslash \mathrm{Kg}$ b. wt. with green tea shows early normal structure too in the central vein. Light microscope magnification is (H\&E X100) stain.

\subsubsection{The portal area alteration}

Our target was verifying that the zonal distribution of hepatic induction when dose with Ciprofibrate $100 \mathrm{mg} \backslash \mathrm{Kg}$ b. wt. around portal areal, and investigation of hepatocytes in the sections of liver acinus how arranged
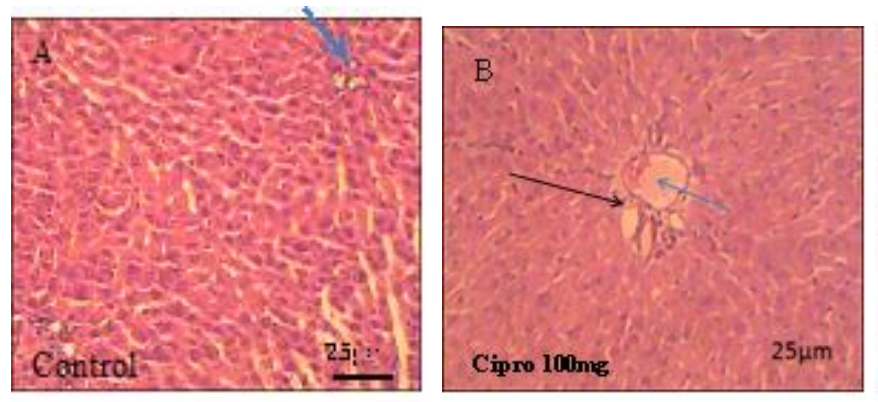

in three areas: Zone 1, 2 and 3. Each zone has a different amount of oxygen which makes it a different response to toxicity. Figure (4) for the Variation in the portal area.
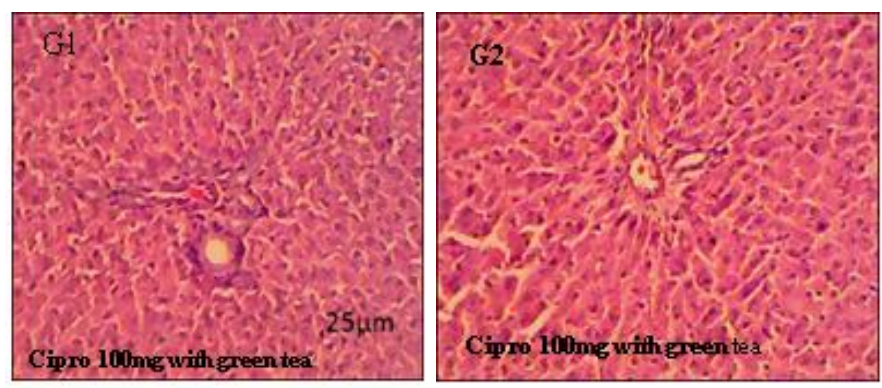
Figure 4. Liver section of 6 rats were gavaged with, $100 \mathrm{mg} \backslash \mathrm{Kg} \mathrm{b}$. et. for ciprofibrate. (A) Section of the liver tissue of control groups shows normal histology structure of portal canal contain branches of portal vein, hepatic artery and bile duct; the triad is clearly bordered by surrounding normal hepatocytes and interlobular septa blue arrow. (B) Section of the liver rat treated with $100 \mathrm{mg} \backslash \mathrm{Kg}$ b.wt. of ciprofibrate shows congestion in portal areal blue arrow with inflammation around portal canal and distraction in hepatocytes surround portal tract black arrow. (G) Section of the liver rat treated with ciprofibrate $100 \mathrm{mg} \backslash \mathrm{Kg}$ b.wt. with green tea shows also improve to portal area. Light microscope magnification is (H\&E X100) stain.

The micrographs below (Figure 5) show disorder in the hepatocytes with gathering to basophilic cells. Apoptosis in liver characterized by scattered
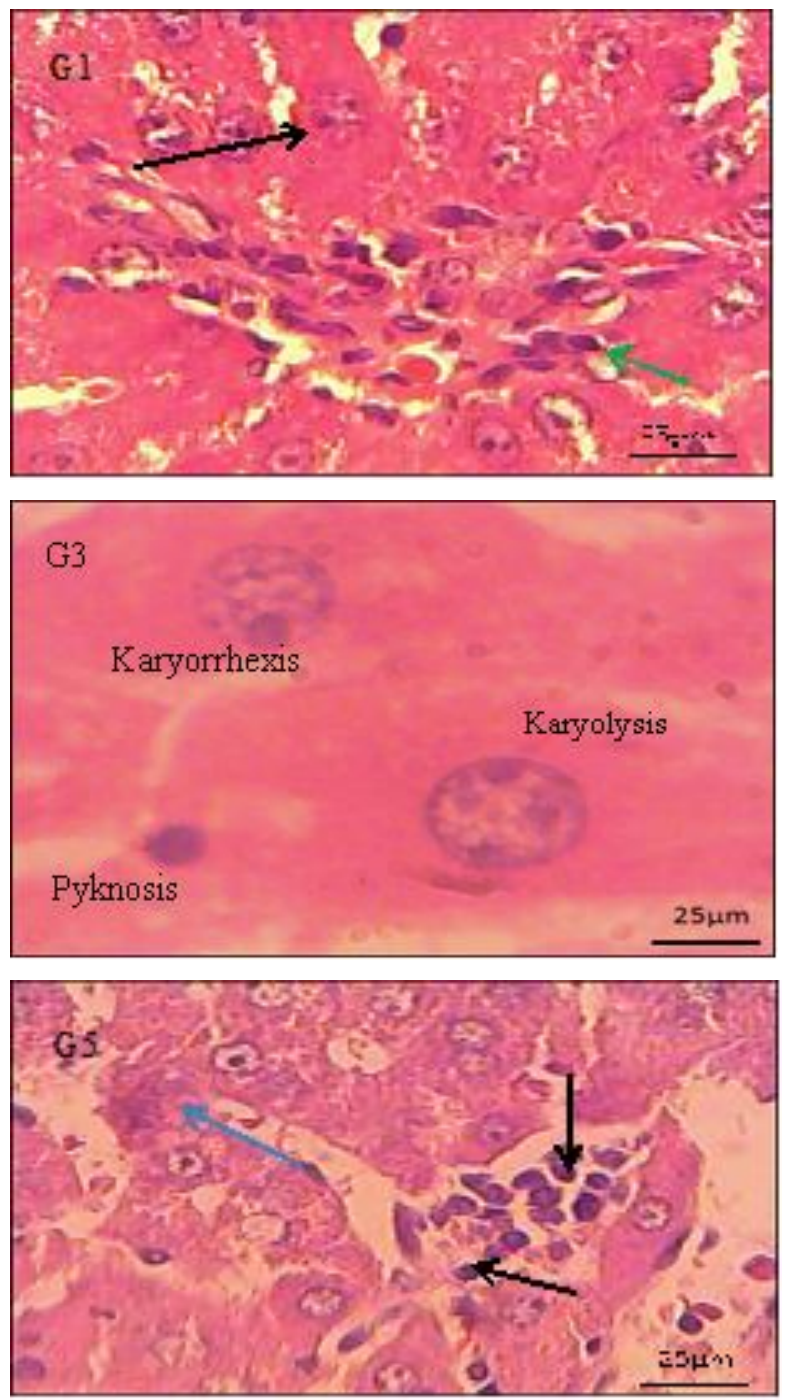

single shows cells of necrosis separately in three different phases, which are pyknosis, karyorrhexis, and karyolysis. The slides were harvested
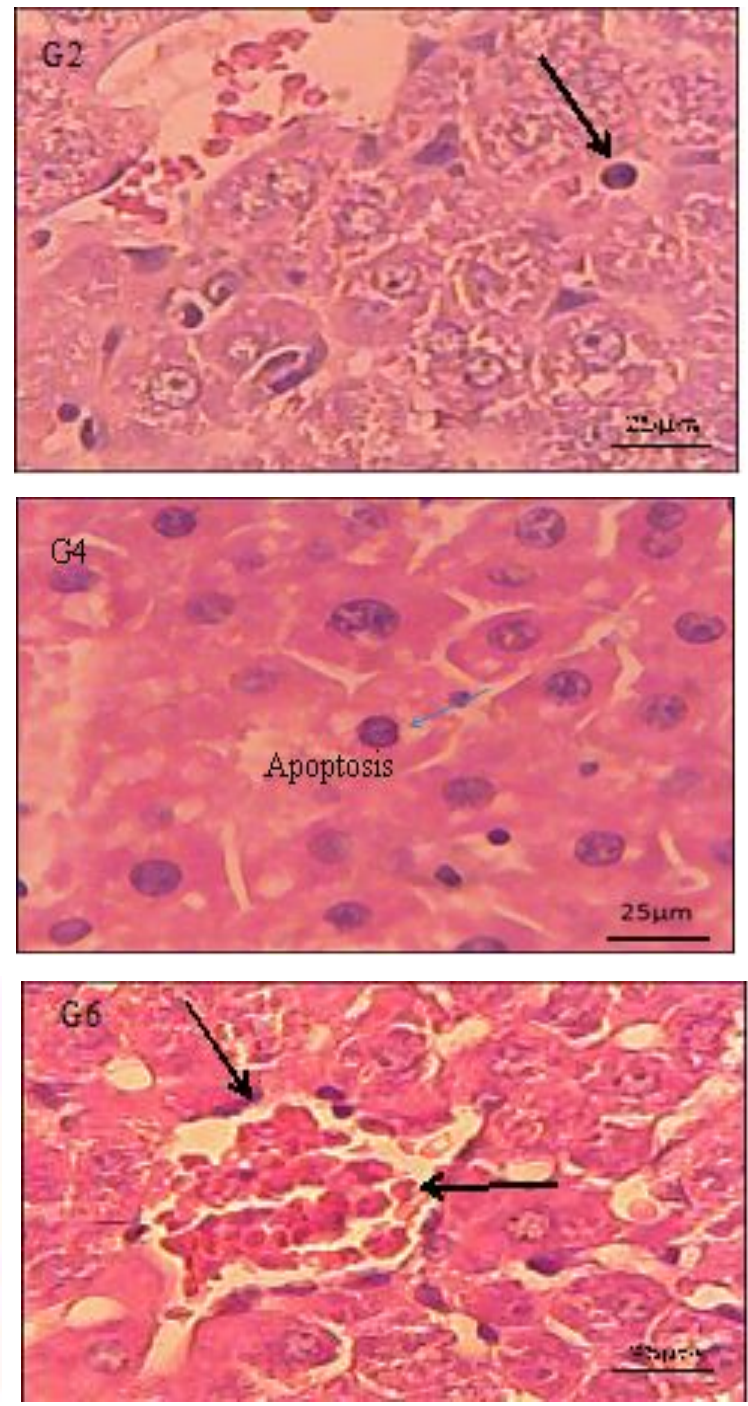

Figure 5. Micrographs of hepatocytes are collected from positive controls that induced andlor ciprofibrate, green with ciprofibrate.

Histopathological changes can be noticed in section G; focal necrosis with inflammatory cells. G1; shows aggregation of inflammatory (green arrow) cells prominent of kupffer cells and apoptotic cells black arrow. G2; apoptosis and distraction in hepatocytes and bleeding (RBCs). G3; shows 3 cells of necrosis separately in three different phases, which are pyknosis, karyorrhexis, and karyolysis. G4; shows clear apoptotic hepatocytes blue arrow and necrosis occurring together in the liver cells black arrow. G5; aggregation of inflammation in sinusoids black arrow and apoptotic cell blue arrow. G6; the black arrow shows cell degeneration and necrosis. Light microscope magnifications are (X40 and X100) H\&E stain.

\section{Discussion}

Peroxisome proliferators are a class of chemicals that have diverse effects in rats and mice including increased DNA synthesis and cause cell proliferation (peroxisome proliferation). These chemicals act through ligand activation of nuclear membrane receptors termed 'peroxisomeproliferator-activated receptors' (PPARs), which themselves act as nuclear transcription factors [31,32].

\subsection{Effect of ciprofibrate on liver enzymes parameters}

Liver function tests showed fluctuate in biochemical parameters. It has emphasized that ciprofibrate 50 and $100 \mathrm{mg}$ had harmful effects on the activities of the serum Alanine aminotransferase, Aspartate aminotransferase, alkaline phosphates, bilirubin total and bilirubin direct in male albino rats compared with the control group. The current study has found an increase in AST with both concentrations, note it was slightly higher at $50 \mathrm{mg} \backslash \mathrm{Kg}$ of Cipro. In addition same condition with 
ALP enzyme, whereas much higher than AST especially at $50 \mathrm{mg} \backslash \mathrm{Kg}$ concentration [33].

\subsection{Enhancement of antioxidants on liver enzymes parameters}

In order to reduce the harmful effect of ciprofibrate, green tea was used as to verify their therapeutic and $\backslash$ or preventive role.

It was known from previous studies in vivo and in vitro, Wistar and Fischer rats (F-344lNHsd) dosed with peroxisome proliferators (nafenopin and Wyeth-14,643) that the hepatic induction of DNA replication starts as early as 24 hours in male rats [10, 33-35].

The peroxisome proliferator (ciprofibrate) is known to cause hepatocarcinogenesis in rats, and it strongly increases hepatic DNA replication of male Fischer rats [36]. Liver cells are damaged when exposed to compounds called free radicals, which are formed in the body as a result of exposure to a type of drug such peroxisome proliferators significantly. It is worth mentioning that this free radical's caused weak and harm to the healthy cells and play a large role in the incidence of cancer.

\subsection{Effect of green tea on liver enzymes parameters in induced rats with ciprofibrate $100 \mathrm{mg} \backslash \mathrm{Kg}$ b. wt.}

Oxidative stress has been proposed as one of the major contributing factor in many diseases development. Ciprofibrate is considered factor reflecting the development of oxidative stress in plasma [37]. This study has tried to reduce the harmful effects of some medications through the use of such antioxidant such as green tea. Green tea is one of strong antioxidants. Intake of it was significantly related to decrease serum concentration enzymes among rats. It has been reported that drinking green tea has a beneficial effect against oxidative stress diseases where reducing the development or the enhancement of oxidative stress. The current study conducted on rats gavaged with dose $100 \mathrm{mg} \backslash \mathrm{Kg} \mathrm{b}$. wt. of ciprofibrate to investigate the role of antioxidants treatment (green tea extract) which showed significant decrease in serum ALT, AST, and ALP. Pezeshki et al., [38] has investigated the potential relationship between green tea consumption and alanine (ALT) and aspartate (AST) aminotransferase. Green tea, consumed worldwide since ancient times, is considered beneficial to human health. Green tea is an important appropriate antioxidant improving the hepatotoxicity [39]. The current study found that green tea caused enhance in serum total bilirubin as well which a consistent with Moller study, this finding explain the important appropriate anti-oxidant improving the hepatotoxicity [40].

\subsection{Histological changes resulting of Ciprofibrate effects and antioxidants treatment}

The histological examination had conducted alongside with liver function tests. Our results revealed liver injury including; bleeding, damage in lining endothelium of central vein and portal area congestion in hepatic sinusoids, destruction in hepatocytes surround portal tract and hepatic necrosis associated with inflammatory cells and focal necrosis. Interestingly, three phases of necrosis were detected nuclear pyknosis, karyorrhexis, and karyolysis for hepatocytes. Hepatocellular necrosis with some specific components of the metabolic pathways leading to the alteration of their structure and function [41]. In addition, the hepatocytes response to the toxic lesion was also reflected by the irregular shape of nuclei and nuclear condensation. Similar results were established in rats by Allen et al., [42]. In this study the effect of administered ciprofibrate led to the injury of the liver in different zones.

In the present work, the focal necrosis and congestion occurred between central vein and portal zone in conditions of deficiency oxygen supply in liver cells and oxidative stress, all above histopathological changes those a resulting of induce liver with ciprofibrate. In the current study; which is green tea, the aim was to investigate the therapeutically effects on the adverse effects of hepatotoxicity as a result ciprofibrate stimulation in
Fischer rats. The rats were pretreated orally gavage (using rats feeding needle) with dose $5 \mathrm{mg} \backslash \mathrm{Kg}$ b. wt. of ciprofibrate with green tea. The antioxidants act to defend against free radicals, (highly reactive and destructive chemicals containing unpaired valence electrons) which can cause damage to cell membranes and DNA that can lead to carcinogenesis (cancer formation). Green tea liquid shows early normal structure too in the central vein and improves to portal area. Green tea polyphenols have been shown to be able to inhibit cancer growth in a wide variety of human and animal tumors is by causing apoptosis to occur in cancer cells whilst not affecting normal healthy cells [43]. Green tea protects against the liver injury caused by ciprofibrate. In view of its antioxidant nature [44].

\section{Conclusions}

The peroxisome proliferators induce a cellular process characterized by a dramatic increase in the size and number of peroxisomes correlated with both hepatocyte hypertrophy (an increase in liver cells size) and hyperplasia or increase in the number of liver cells during replicative DNA synthesis and cell division. The current study investigated the beneficial effects of green tea on liver injuries induced by peroxisome proliferators (ciprofibrate). This study provides accurate analyses of the potential effects of ciprofibrate on liver enzymes and the histological effects. The study showed valued results through study of biochemistry parameters and histological disease. Previous studies have addressed the effects of peroxisome proliferators, while the current study confirmed most of the previous results. In addition, in this experiment antioxidant (green tea) was used to reduce the toxicological effects of the drug. The antioxidant have shown inhibition to the hepatotoxicant induced liver injuries in rodents.

\section{References}

1. Grijalva J. and Vakili K. (2013). Neonatal liver physiology. Semin. Pediatr. Surg. 22, 185-189.

2. Hyder, M. A., Hasan, M. and Mohieldein, A. H. (2013) Comparative levels of ALT, AST, ALP and GGT in liver associated diseases. European j of experimental biology, 3(2), pp. 280-284.

3. Banerjee, R. R. et al. (2004) Regulation of fasted blood glucose by resistin. Science. American Association for the Advancement of Science, 303(5661), pp. 1195-1198.

4. Vanhove, G. F. et al. (1993) The CoA esters of 2-methyl-branched chain fatty acids and of the bile acid intermediates di-and trihydroxycoprostanic acids are oxidized by one single peroxisomal branched chain acyl-CoA oxidase in human liver and kidney. Journal of Biological Chemistry. ASBMB, 268(14), pp. 1033510344.

5. Steals B, Dallongeville J, Aureux J, Schoonjans K, Leitersdorf E, Fruchart JC. (1998). Mechanism of action of fibrates on lipid and lipoprotein metabolism. Circulation. 98:2088-2093.

6. Kliewer, S. A. et al. (1997) Fatty acids and eicosanoids regulate gene expression through direct interactions with peroxisome proliferator-activated receptors $\alpha$ and $\gamma$ Proceedings of the National Academy of Sciences. National Acad Sciences, 94(9), pp. 43184323.

7. Mannaerts, G. P. and Van Veldhoven, P. P. (1993) Metabolic pathways in mammalian peroxisomes. Biochimie. Elsevier, 75(34), pp. 147-158.

8. Rao, M. S. and Subbarao, V. (1997) Effect of dexamethasone on ciprofibrate-induced cell proliferation and peroxisome proliferation. Toxicological Sciences. Oxford University Press, 35(1), pp. 78-83.

9. Ozer, J. et al. (2008) The current state of serum biomarkers of hepatotoxicity. Toxicology Elsevier, 245(3), pp. 194-205.

10. Al Kholaifi, A. et al. (2008) Species-specific kinetics and zonation of hepatic DNA synthesis induced by ligands of PPAR $\alpha$, 
Toxicological sciences. Oxford University Press, 104(1), pp. 7485.

11. de Araújo, R. F., Martins, D. B. G., \& Borba, M. A. C. (2016). Oxidative stress and disease. In A master regulator of oxidative stress-the transcription factor nrf2. Intech Open. DOI: $10.5772 / 65366$

12. Roychoudhury S, Agarwal A, Virk G, Cho CL. (2017). Potential role of green tea catechins in the management of oxidative stressassociated infertility. Reprod Biomed Online, 34:487-98.

13. Coimbra, S. et al. (2006) The effect of green tea in oxidative stress. Clinical Nutrition. Elsevier, 25(5), pp. 790-796.

14. Park HJ, Lee JY, Chung MY, Park YK, Bower AM, Koo SI, Giardina C, Bruno RS. (2012). Green tea extract suppresses NFkappaB activation and inflammatory responses in diet-induced obese rats with nonalcoholic steatohepatitis. J Nutr. 142: 57-63.

15. Gan, R.Y.; Li, H.B.; Sui, Z.Q.; Corke, H. (2018). Absorption, metabolism, anti-cancer effect and molecular targets of epigallocatechin gallate (EGCG): An updated review. Crit. Rev. Food Sci. Nutr., 58, 924-941.

16. Cooper R., Morre D.J. and Morre D.M. (2005). Medicinal benefits of green tea: Part I. Review of noncancer health benefits. J. Altern. Complement. Med., 11: 521-528.

17. Crespy, V. and Williamson, G. (2004). A review of the health effects of green tea catechins in in vivo animal models. J. Nutr., 134: 3431S-3440S.

18. Xu, X.Y.; Zhao, C.N.; Cao, S.Y.; Tang, G.Y.; Gan, R.Y.; Li, H.B. (2020). Effects and mechanisms of tea for the prevention and management of cancers: An updated review. Crit. Rev. Food Sci. Nutr. 60(10): 1693-1705.

19. Awoniyi, D.O., Aboua, Y.G. Marnewick, J., and Brooks, N. (2012). The effects of Rooibos (Aspalathus linearis), Green tea (Camellia sinensis) and commercial Rooibos and Green tea supplements on epididymal sperm in oxidative stress-induced rats. Phytother. Res. 26: 1231-1239.

20. Serafini M, Del Rio D, Yao DN, Bettuzzi S, and Peluso I. (2011). Chapter 12. Health benefits of tea. In: Benzie IFF, Wachtel-Galor S (eds). Herbal Medicine: Biomolecular and Clinical Aspects, 2nd edn. CRC Press $\backslash$ Taylor \& Francis: Boca Raton (FL).

21. Peluso I., and Serafini M. (2017). Antioxidants from black and green tea: From dietary modulation of oxidative stress to pharmacological mechanisms. Br. J. Pharmacol. 174:1195-1208

22. Del Rio D., Stewart A.J., Mullen W., Burns J., Lean M.E.J., Brighenti F., Crozier A. (2004). HPLC-MSnAnalysis of Phenolic Compounds and Purine Alkaloids in Green and Black Tea. J. Agric. Food Chem. 52:2807-2815.

23. Tsuneki, H., Ishizuka, M., Terasawa, M. et al. (2004). Effect of green tea on blood glucose levels and serum proteomic patterns in diabetic (db\db) mice and on glucose metabolism in healthy humans. BMC Pharmacol., 4 (1): 18

24. Inami, S.; Takano, M.; Yamamoto, M.; Murakami, D.; Tajika, K.; Yodogawa, K.; Yokoyama, S.; Ohno, N.; Ohba, T.; Sano, J.; et al. (2007). Tea catechin consumption reduces circulating oxidized low-density lipoprotein. Int. Heart J. 48, 725-732.

25. Peluso I, Teichner A, Manafikhi H, Palmery M. (2015). Camellia Sinensis in Asymptomatic Hyperuricaemia: A Meta-analysis of Tea or Tea Extract Effects on Uric Acid Levels. Crit Rev Food Sci Nutr.

26. Albokhadaim, I. (2016) Effect of aqueous extract of green tea (Camellia sinensis) on hematology and oxidative stress biomarkers in rats intoxicated with carbon tetrachloride. J Biol Sci, 16(3): 4957.

27. Kanlaya,R., and Thongboonkerd,V. (2019). Protective Effects of Epigallocatechin-3-Gallate from Green Tea in Various Kidney Diseases. Advances in Nutrition, 10(1): 112-121
28. Luo, D., Xu, J., Chen, X. et al. (2020). (-)-Epigallocatechin-3gallate (EGCG) attenuates salt-induced hypertension and renal injury in Dahl salt-sensitive rats. Sci Rep 10: 4783.

29. Abushofa, F. A., Bell, D. R. and Dyer, P. S. (2015) Mechanism of Action of Liver Growth Induced By Non-Genotoxic Carcinogens (Peroxisome Proliferators)'.

30. Khan, S. A., Priyamvada,S., Farooq, N., Khan, S., Khan, M. W., Yusufi, A. N. K. (2009). Protective effect of green tea extract on gentamicin-induced nephrotoxicity and oxidative damage in rat kidney. Pharmacological Research, 59: 254 -262.

31. Vanden Heuvel, J. P. et al. (2006). Differential activation of nuclear receptors by perfluorinated fatty acid analogs and natural fatty acids: a comparison of human, mouse, and rat peroxisome proliferator-activated receptor- $\alpha,-\beta$, and $-\gamma$, liver $X$ receptor- $\beta$, and retinoid X receptor- $\alpha$ ', Toxicological Sciences. Oxford University Press, 92(2): 476-489.

32. Darnell Jr, J. E. (2002) Transcription factors as targets for cancer therapy. Nature Reviews Cancer. Nature Publishing Group, 2(10): 740 .

33. Abushofa, F. A. A. (2014) Studies on the role of peroxisome proliferators: in liver growth and neurodegenerative disorders. University of Nottingham.

34. Ledda-Columbano, G. M. et al. (1998) In vivo hepatocyte proliferation is inducible through a TNF and IL-6-independent pathway. Oncogene. Nature Publishing Group, 17(8): 1039.

35. Muenchen, H. J. and Pienta, K. J. (1999) The role of the nuclear matrix in cancer chemotherapy. Critical Reviews TM in Eukaryotic Gene Expression. Begel House Inc., 9(3-4).

36. Bursch, W. et al. (1984) Controlled death (apoptosis) of normal and putative preneoplastic cells in rat liver following withdrawal of tumor promoters Carcinogenesis. Oxford University Press, 5(4), pp. 453-458.

37. Sun, F. et al. (2000) Evaluation of oxidative stress based on lipid hydroperoxide, vitamin $\mathrm{C}$ and vitamin $\mathrm{E}$ during apoptosis and necrosis caused by thioacetamide in rat liver. Biochimica et Biophysica Acta (BBA)-Molecular Basis of Disease. Elsevier, 1500(2): 181-185.

38. Pezeshki, A. et al. (2016) The effect of green tea extract supplementation on liver enzymes in patients with nonalcoholic fatty liver disease. International journal of preventive medicine. Wolters Kluwer--Medknow Publications, 7.

39. Safer, A. M. and Al-Nughamish, A. J. (1999) Hepatotoxicity induced by the anti-oxidant food additive, butylated hydroxytoluene BHT, in rats. An electron microscopical study Histology and histopathology. Murcia: F. Hernández.

40. Erel, O. (2004) A novel automated direct measurement method for total antioxidant capacity using a new generation, more stable ABTS radical cation. Clinical biochemistry. Elsevier, 37(4): 277285.

41. Suzanne, M. et al. (1984) Midzonal necrosis as a pattern of hepatocellular injury after shock. Gastroenterology. Elsevier, 86(4): 627-631.

42. Allen, J. W., Khetani, S. R. and Bhatia, S. N. (2004) In vitro zonation and toxicity in a hepatocyte bioreactor, Toxicological sciences. Oxford University Press, 84(1): 110-119.

43. Pillai, S. P. et al. (1999) Antimutagenic/antioxidant activity of green tea components and related compounds. Journal of environmental pathology, toxicology and oncology: official organ of the International Society for Environmental Toxicology and Cancer, 18(3): 147-158.

44. Abdel-Dayem, M. A. et al. (2014) Valproate-induced liver injury: modulation by the omega-3 fatty acid DHA proposes a novel anticonvulsant regimen, Drugs in R\&D. Springer, 14(2): 85-94. 